\section{Jurnal Pendidikan Sosial Keberagaman}

Print-ISSN 2355-4622 Online-ISSN 2622-9021

Vol. 7, No. 2, Oktober-Maret 2020, hh. 88-94

https://juridiksiam.unram.ac.id/index.php/juridiksiam

\title{
INTENSITAS PEMAHAMAN MAHASISWA TENTANG PENGAMALAN PANCASILA BERDASAR ATAS BERKAT RAHMAT ALLAH YANG MAHA KUASA
}

\author{
Arlis $^{1}$ \\ Prodi Hukum Tata Negara Fakultas Syari'ah UIN Imam Bonjol Padang ${ }^{1}$ \\ Email: arlisshi@ uinib.ac.id
}

\begin{abstract}
ABSTRAK
Atas berkat rahmat Allah Yang Maha Kuasa adalah ketentuan yang terdapat dalam pembukaan konstitusi negara Indonesia. Berdasarkan ketentuan tersebut rakyat Indonesia menyatakan kemerdekaannya. Dengan dasar itu pula muncul pendapat Indonesia berdasar Pancasila. Oleh sebab itu, menjadi sangat penting untuk mengetahui intensitas pemahaman mahasiswa tentang pengamalan Pancasila berdasar atas berkat rahmat Allah Yang Maha Kuasa. Pemilihan mahasiswa sebagai kajian tidak lain disebabkan karena mahasiswa berada di garda terdepan sebagai agen perubahan. Mahasiswa dalam kajian ini adalah mahasiswa Fakultas Keguruandan Ilmu Pendidikan Universitas Mahaputra Muhammad Yamin Solok angkatan 2019. Tujuan penelitian adalah pengetahuan intensitas pemahaman mahasiswa Universitas Mahaputra Muhammad Yamin tentang pengamalan Pancasila berdasar atas berkat Rahmat Allah Yang Maha Kuasa. Metode penelitianyang digunakan adalah campuran kualitatif dan kuantitatif dengan data primer, teknik pengumpulan data melalui kuesioner. Temuan utama penelitian adalah terdapat keberagaman intensitas pemahaman mahasiswa tentang pengamalan Pancasila berdasar atas berkat rahmat Allah Yang Maha Kuasa. Keberagaman itu dimulai dari Konsep pengamalan Pancasila itu sendiri, aplikasikonsep dan contoh aplikatifnya.Berdasarkan temuan penelitian diperoleh kesimpulan bahwa intensitas pemahaman mahasiswa tentang pengamalan Pancasila berdasar atas berkat rahmat Allah Yang Maha Kuasa beragam dengan berbagai dinamikanya.
\end{abstract}

Kata kunci : Intensitas, Pemahaman, Pancasila, Berkat, Allah

\section{PENDAHULUAN}

Atas berkat rahmat Allah Yang Maha Kuasa adalah ketentuan yang terdapat dalam pembukaan konstitusi negara Indonesia. Alinea ketiga Undang-Undang Dasar Negara Republik Indonesia Tahun 1945 menyebutkan bahwa "Atas berkat rakhmat Allah Yang Maha Kuasa dan dengan didorongkan oleh keinginan luhur, supaya berkehidupan kebangsaan yang bebas, maka rakyat Indonesia menyatakan dengan ini kemerdekaannya." Ketentuan dimaksud menurut Mas'udi (2013: 3) merupakan perihal semangat keimanan kepada Tuhan Yang Maha Esa, sebagai landasan spritual-moral seluruh gerak dan perjuangan bangsa dalam membangun negara. Allah adalah Tuhan semesta alam (Lajnah, 2019). Berdasarkan ketentuan tersebut rakyat Indonesia menyatakan kemerdekaannya (Pardi, 2019: 99-101). Dengan dasar itu pula muncul pendapat Indonesia berdasar Pancasila (Pahlevi: 2016). Oleh sebab itu, menjadi sangat penting untuk mengetahui intensitas pemahaman mahasiswa tentang pengamalan Pancasila berdasar atas berkat rahmat Allah Yang Maha Kuasa. Pemilihan mahasiswa sebagai kajian tidak lain 
disebabkan karena mahasiswa berada di garda terdepan sebagai agen perubahan (Rifandi, dkk: 59-60).

Teori yang digunakan dalam penelitian ini adalah teori maslahat. Maslahat merupakan tujuan utama atau inti dari pensyariatan hukum bagi manusia agar bahagia dunia dan akhirat. Peran maslahat sangat besar dalam pembentukan hukum dalam setiap waktu dan kondisi (AlHasani: 2016). Teori maslahat dapat menjadi model strategis. Implementasi teori maslahat dapat menjadi metode penggalian hukum paling tepat untuk kebutuhan. Maslahat juga dianggap sebagai sistem nilai yang berkeadilan dan relevan dengan situasi dan konteks zaman (Zainuddin: 2019). Mahasiswa dalam kajian ini adalah mahasiswa Fakultas Keguruan dan Ilmu Pendidikan Universitas Mahaputra Muhammad Yamin Solok angkatan 2019. Pemilihan mahasiswa ini di antaranya adalah faktor akses untuk mendapatkan data penelitian. Tujuan penelitian adalah pengetahuan intensitas pemahaman mahasiswa Universitas Mahaputra Muhammad Yamin tentang pengamalan Pancasila berdasar atas berkat Rahmat Allah Yang Maha Kuasa.

Dapat diketahui kaitan penelitian ini dengan penelitian sebelumnya, di antaranya penelitian Agustan Ahmad tentang maqāṣid al-syarī'ah al-Syāṭibī dan aktualisasinya dalam nilainilai falsafah Pancasila. Pembahasan dalam tulisannya berangkat dari masalah pokok, yaitu apa dan bagaimana maqāṣid al-syarī'ah menurut al-Syāṭibī dan aktualisasinya dalam nilai-nilai falsafah Pancasila (Ahmad, 2011). Penelitian Agustan Ahmad bersifat normatif, sedangkan kajian ini adalah penelitian hukum empiris. Manfaat yang diperoleh dengan penelitian ini dapat dikategorikan kepada manfaat teoretis dan praktis. Manfaat teoretis penelitian ini adalah memperoleh dan menambah wawasan dan pengetahuan. Sedangkan manfaat praktisnya adalah dapat berguna untuk peningkatan intensitas pemahaman mahasiswa tentang pengamalan Pancasila berdasar atas berkat Rahmat Allah Yang Maha Kuasa.

\section{METODE}

Metode penelitian yang digunakan adalahdesain penelitian hukum empiris. Populasinya adalah mahasiswa Fakultas Keguruan dan Ilmu Pendidikan Universitas Mahaputra Muhammad Yamin Solok angkatan 2019. Sampel ditentukan berdasarkan mahasiswa yang meberkan jawaban pertanyaan penelitian yaitu sebanyak $81 \%$ dari populasi yang bergabung di grup whatsapp. Sampel mahasiswa tersebut terdiri dari 13 orang mahasiswa program studi Pendidikan Bahasa Indonesia, 5 orang mahasiswa program studi Pendidikan Biologi, 2 orang mahasiswa program studi Pendidikan Matematika, 13 orang mahasiswa program studi Pendidikan Ekonomi, dan 10 orang mahasiswa program studi Pendidikan Bahasa Inggris.

Instrumen penelitian menggunakan google formulir. Prosedur pengumpulan data adalah dengan mengirimkan kuesioner penelitian di grup mahasiswa, selanjutkan mahasiswa menjawab dengan mengisi google formulir tersebut. Pemilihan prosedur ini tidak lain disebabkan karena kondisi pandemi covid-19 yang melahirkan kebijakan Pembatasan Sosial Berskala Besarsehingga tidak memberi ruang untuk mengumpulkan data secara tatap muka. Data dianalisis dengan analisia kuantitatif dan kualitatif.

\section{HASIL DAN PEMBAHASAN}

Hasil Penelitian

1. Pemahaman Mahasiswa tentang Pengamalan Pancasila Berdasar Atas Berkat Rahmat Allah Yang Maha Kuasa 
Mahasiswa memaknai kalimat atas berkat Rahmat Allah Yang Maha Kuasa dengan: pertama, atas cinta Allah Yang Maha Kuasa (2,4\%); kedua, atas karunia belas kasih Allah Yang Maha Kuasa (28,6\%); dan ketiga, atas nikmat Allah Yang Maha Kuasa (69\%). Sementara itu tidak ada mahasiwa yang memilih jawaban bahwa makna kalimat itu adalah atas sayang Allah Yang Maha Kuasa (0\%).

Seluruh mahasiswa meyakini dan sepakat memberikan jawaban bahwa hukum mentaati ketentuan Allah Yang Maha Kuasa adalah wajib (100\%). Hal ini dapat dilihat gambar berikut ini.

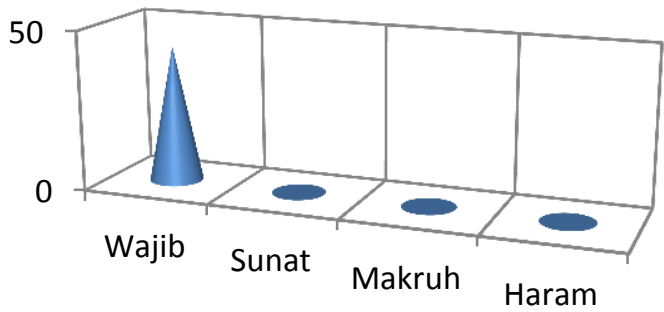

\section{Gambar1. Hukum Taat Aturan Allah}

Hasil penelitian menunjukkan pada umumnya mahasiswa menyatakan bahwa pengamalanPancasilatidak boleh bertentangandenganketentuan Allah Yang Maha Kuasa.

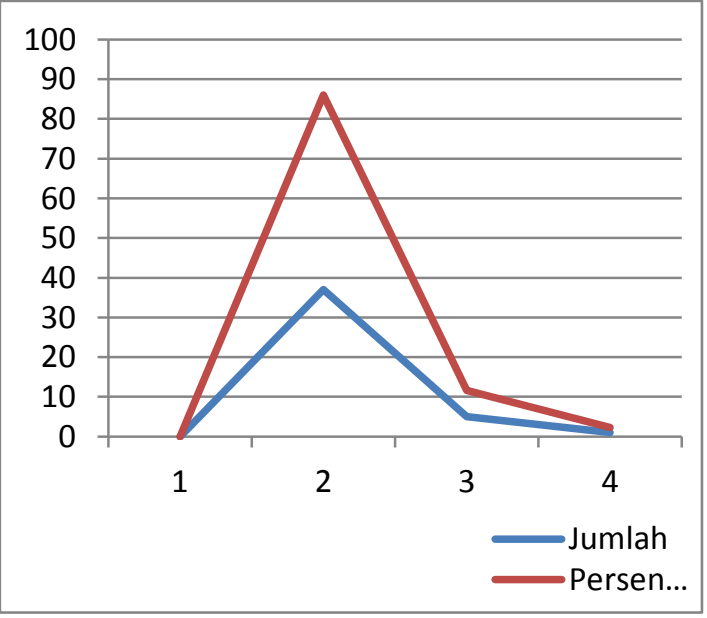

\section{Grafik 1.Pengamalan Pancasila}

Berdasarkan grafik di atas dapat diketahui bahwa tidak seorangpun mahasiswa (Angka 1) yang menyatakan bolehpengamalan Pancasila bertentangan dengan ketentuan Allah Yang Maha Kuasa (0/0\%). Sedangkan sebanyak 37 (Angka 2) mahasiswa (86\%)menyatakan bahwa pengamalanPancasilatidak boleh bertentangandenganketentuan Allah Yang MahaKuasa. Sebanyak 5 orang mahasiswa (Angka 3) menyatakan bahwa boleh atau tidak bolehnya pengamalan Pancasila tidak boleh bertentangan dengan ketentuan Allah Yang Maha Kuasa adalah tergantung kondisi (11,6\%). Hanya seorang mahasiswa (Angka 4) yang menyatakan tidak tahu $(2,3 \%)$. 


\section{Tingkat Pemahaman Mahasiswa tentang Pengamalan Pancasila Berdasar Atas Berkat Rahmat Allah Yang Maha Kuasa}

Salah satu hal yang sangat menarik terungkap melalui hasil penelitian ini adalah tentang pelaksanaan shalat fardhu bagi umat Islam dalam hubungannya dengan pengamalan Pancasila atas berkat rahmat Allah Yang Maha Kuasa. Apakah melaksanakanshalatfardhubagiumat Islam merupakanbentukpengamalanPancasila.

Hasil ini begitu penting untuk diungkapkan karena Shalat Fardhu hukumnya adalah fardhu 'Ain. Dengan pengertian bahwa setiap pribadi muslim yang sudah cakap hukum wajib hukumnya melaksanakan shalat fardhu lia waktu sehari semalam. Berdosa ketika tidak dilaksanakan. Bahkan intensitas pelaksanaan shalat menjadi ukuran seluruh aktivitas kehidupan.

Tingkat pemahaman mahasiswa tentang hal ini dapat dilihat pada tabel berikut ini.

\begin{tabular}{|c|l|c|c|}
\hline No & \multicolumn{1}{|l|}{ Jawaban } & Jumlah & $\%$ \\
\hline 1 & Benar & 36 & 83,7 \\
\hline 2 & Tidak Benar & 3 & 7 \\
\hline 3 & Tidak tahu & 0 & 0 \\
\hline 4 & Ragu-ragu & 4 & 9,3 \\
\hline
\end{tabular}

\section{Tabel 1.Shalat Merupakan Bentuk Pengamalan Pancasila}

Tabel menunjukkan bahwa sebanyak 36 mahasiswa memahami melaksanakan shalat fardhu bagi umat Islam merupakan bentuk pengamalan Pancasila. Sedangkan 4 orang mahasiswa menyatakan ragu-ragu dan 3 orang lainnya menyatakan tidak benar. Secara menyeluruh penting menjadi perhatian dan pembahasan adalah hasil penelitian tingkat intensita spemahamanmahasiswa tentang pengamalan Pancasila berdasar atas berkat rahmat Allah Yang Maha Kuasa yang menunjukkan keberagaman. Hal ini diketahui melalui jawaban mahasiwa yang menyebutkan bahwa mereka (10 mahasiswa) memiliki tingkat pemahaman yang tinggi (23,3\%); 30 orang mahasiswa menyatakan memiliki pemahaman sedang $(63,8 \%)$ dan selebihnya (3 mahasiswa) menyatakan tidak tahu (7\%).

\section{Pembahasan}

Berdasarkan hasil penelitian diketahui bahwa intensitas pemahamanan mahasiswa tentang pengamalan Pancasila berdasar atas berkat rahmat Allah Yang Maha Kuasa memilki relevansi dengan teori maslahah pada tingkatan tertinggi. Pengetahuan ini diperoleh dengan data bahwa seluruh mahasiswa (100\%) meyakini dan memahami bahwa hukum mentaati ketentuan Allah Yang Maha Kuasa adalah wajib. Berkenaan dengan hal ini, Allah Maha Kuasa melalui kalamNya yang dielaborasi oleh Tim Lajnah Pentashih Kemenag RI mencantumkan sebanyak 4.264 kata Allah disebut dalam Al-Qur'an dan terjemahannya. Allah Swt. disebut rabb (Tuhan) seluruh alam karena Dialah yang telah menciptakan, memelihara, mendidik,mengatur, mengurus, memberi rezeki, dan sebagainya kepada semua makhluk-Nya (Lajnah, 2019).

Allah menyebutkan Diri-Nya sebagai Zat Yang Tunggal (QS. An-Nahl [16]: 22). Pengakuan sifat kemanusiaan akan eksistensi Zat Yang Maha Tunggal menunjukkan sebuah 
konsep monoteisme (QS. Al-Ikhlas). Konsep ini menuntut sebuah pengakuan akan perbedaan manusia yang plural dengan Tuhan Yang Maha Tunggal. Berbeda sifat, manusia berasal dariNya dan menuju pada-Nya. Pengakuan Tuhan Yang Maha Esa sekaligus menutup adanya pengakuan ketiadaan Tuhan (Herdiawanto, dkk. 2018: 121). Pengakuan atas eksistensi ini tidak sekadar diletakkan dalam gagasan ruang ide semata, tetapi jauh merasuk pada sisi materi manusia terdalam, yaitu jiwa. Manusia merasakan bahwa ia bersama dengan Tuhannya dan menjadi milik-Nya. Hal ini memunculkan sebuah keyakinan bahwa Tuhan adalah permulaan dan dengan-Nya ia tertolong dan diteguhkan. Kepada-Nya tujuan dan akhir manusia. Bersama-Nya ia bertawakkal dan bersandar. Pengakuan akan keesaan Tuhan dalam sila pertama Pancasila adalah urat tunggang keseluruhan sila Pancasila. Ia menjiwai sila-sila yang ada dalam Pancasila (Herdiawanto, dkk. 2018: 123).

Berkenaan dengan pelaksanaan shalat Fardhu ini adalah bentuk ketaatan kepada Hukum Allah Yang Maha Kuasa. Maka manusia Muslim Pancasila wajib menjalankannya. Dengan pemaknaan lebih lanjut dalam konteks ini, seseorang dikatakan Pancasilais jika ia melaksanakan shalat dengan benar. Ini lah jalan lurus. Jalan yang lurus adalah jalan hidup yang benar sesuai dengan ajaran Islam yang terkandung di dalam Al-Qur'andan hadis (Lajnah, 2019). Allah memberikan peringatan diawali dengan melontarkan pertanyaan"Siapakah yang lebih menepati janjinya daripada Allah?"Berikutnya Allah lanjutkan: "Maka,bergembiralah dengan jual beli yangtelah kamu lakukan itu. Demikian itulahkemenanganyang agung. (Mereka itulah) orangorang yang bertobat,beribadah, memuji (Allah), mengembara (demi ilmu dan agama),rukuk dan sujud, menyuruh berbuatmakruf dan mencegah berbuat mungkar,serta memelihara hukumhukum Allah.Sampaikan kabar gembira kepada orang-orangyang beriman (Lajnah, 2019).”

Perlindungan terhadap mashlahah terdiri dari 5 (lima) mashlalah, yaitu keimanan (ad-din), ilmu (al-ilm), jiwa (an-nafs), harta (al-mal) dan kelangsungan keturunan (annasl).Seluruhnyamerupakan sarana yang sangat dibutuhkan bagi kelangsungan hidup. Jika salah satu dari lima kebutuhan ini tidak tercukupi niscaya manusia tidak akan mencapai kesejahteraan yang sesungguhnya (Bahsoan. 2011). Koherensi teori maslahah dengan pemahaman Pancasila diketahui bahwa sila pertama Pancasila-Ketuhanan Yang Maha Esa-mencerminkam konsep tauhid. Sila ini merupakan dasar moral dan dasar keruhanian masyarakat, bangsa, dan negara. Penyelenggaraan kehidupan berbangsa dan bernegara wajib menghargai, menghormati, dan melaksanakan petunjuk Allah Yang Maha Kuasa. Seluruh peraturan perundang-undangan dan peraturan kebijakan penguasa wajib merujuk kepada ketentuan Allah (Ahmad, 2011).

Asas Ketuhanan yang Maha Esa menghendaki supaya penduduk Indonesia memakaikan aturan Tuhan yang Maha Esa dalam kehidupan. Penduduk harus tolong menolong dan menerapkan prinsip hidup rukun dan toleransi beragama dan beribadat.Kondisi ini sejalan dengan aturan Islam Al-Qur'an dan Sunnah. Ketentuan Allah Yang Maha Kuasa memberikan tuntunan lengkap dan praktis tentang Kemanusiaan yang adil danberadab. Halini tercermin dalam beberapa ayat Al-Quran dan SunnahRasulullah saw. yang menghargai dan menghormati keberadaan manusia dengan fitrahnya. Bahkan sangat patut menjadi kesadaran bersama bahwa hak asasi manusia adalah anugerah Allah Yang Maha Kuasa(Ahmad, 2011). Sila ketiga Pancasila -Persatuan Indonesia- merupakan syarat hidupbagi bangsa Indonesia yang pada hakikatnya mengandung prinsipnasionalisme, unsur-unsur persatuan dan kesatuan,keindonesiaan, dan cita-cita persahabatan dengan segala bangsa. Allah Tuhan Yang Maha Kuasa menuangkan ajaran tentang persatuan dan kesatuan dalam banyak firman-Nya yang 
mengajakmanusia untuk tidak saling berprasangka buruk, tidak bertengkar,tetapi — sebaliknyadiminta untuk bersatu karena manusia padahakikatnyaberasal dari keturunan yang satu dengan Tuhan yangsatu pula. Prasangka kebangsaan atas dasar rasisme,sektarianisme, serta memandang bangsa tertentu lebih tinggimartabat daripada bangsa lain, merupakan paradigma yangsangat betentangan dengan fitrah dan kodrat manusia.

Sila keempat, Kerakyatan yang dipimpin oleh hikmat kebijaksanaandalam permusyawaratan/perwakilan. Sesuai dengan pemaknaan Sila Ketuhanan yang Maha Esa adalah urat tunggang Pancasila, maka kerakyatan berartikerakyatan yang berlandaskan atas berkat rahmat Tuhan Yang Maha Kuasa; bukandemokrasi liberal. Kerakyatan berarti bahwa penyelenggaraankehidupan berbangsa harus dilakukan dengan musyawarah yangmengacu pada aturan-aturan yang ditetapkan oleh Al-Quran dan Sunnah. Tujuan akhir dari musyawarah adalah untuk mencapai mufakatdengan menjunjung tinggi nilai-nilai ketuhanan dan kemanusiaan(Ahmad, 2011).

Sila kelima, keadilan sosial bagi seluruh rakyat Indonesia. Keadilanyang berorientasi pada kemaslahatan sosial bukan saja menjadidasar negara, melainkan sekaligus menjadi tujuan yang harusdilaksanakan. Pada prinsipnya, sila Keadilan Sosial menghendakiadanya kemakmuran yang merata bagi seluruh rakyat Indonesia.Apabila keadilan diartikan memberikan kepada seseorang apayang menjadi hak-haknya, keadilan sosial berarti memberikankepada anggota masyarakat apa yang menjadi haknya atas dasarkelayakan dan keseimbangan. Al-Quran mengajarkan agar orangberbuat adil, berbuat iḥsān, memberikan hak karib kerabat, tidak berbuat keji, kemungkaran, dan permusuhan(Ahmad, 2011).

Pemahaman Pancasila berdasarkan atas berkat rahmat Allah Yang Maha Kuasa, seperti yang diuraikan diatas, mengisyaratkan adanya hubungan-hubungan yang berimplikasi pada keseimbangan hak dan kewajiban yang merupakan titik-tolak terwujudnya kemaslahatan.Hubungan manusia dengan Allah Tuhan Yang Maha Kuasa, hubungan manusia dengan sesama, dan hubungan manusia dengan lingkungannya. Maslahat yang dimaksus, tidak lain adalah demi kemaslahatan hidup pribadi, keluarga, masyarakat, dan bangsa Indonesia dunia dan akhirat.

\section{KESIMPULAN}

Kesimpulan penelitian ini adalah intensitas pemahaman mahasiswa tentang pengamalan Pancasila berdasar atas berkat rahmat Allah Yang Maha Kuasa beragam dengan berbagai dinamikanya. Beragamnya intensitas pemahaman mahasiswa ini tidak lepas dari wawasan masing-masing mahasiswa dimaksud tentang Pancasila dan makna atas berkat rahmat Allah Yang Maha Kuasa dengan seluruh konsekuensinya.

Hasil penelitian ini sangat prospektif untuk dikembangkan karena atas berkat rahmat Allah Yang Maha Kuasa adalah landasan lahirnya Indonesia merdeka. Kajian intensitas selalu relevan dilaksanakan karena secara faktual mengungkap kondisi apa adanya yang untuk selanjutnya secara teori dibedah sehingga diperoleh konsep sebagai upaya peningkatannya.

Sebagai bentuk rekomendasi dari hasil penelitian ini agar berbagai komponen dan elemen bangsa betul-betul menggiatkan studi secara umum, studi Pancasila khususnya dengan mengedepankan konsep intensitas. Secara spesifik dalam konteks pemahaman mahasiswa agar dilaksanakan sosialiasi ke seluruh perguruan tinggi dengan program terukur dan sistematis dalam rangka perwujudan syukur atas berkat rahmat Allah Yang Maha Kuasa. Sehingga studi dimaksud 
sangat mungkin diharapkan sebagai bagian ibadah yang menghadirkan maslahat hidup di dunia dan akhirat.

\section{PUSTAKA RUJUKAN}

\section{ArtikelJurnal:}

Ahmad, Agustan. (2011). Maqāṣid al-Syarī'ah al-Syāțibī dan Aktualisasinya dalam Nilai-nilai Falsafah Pancasila. Hunafa: JurnalStudiaIslamika. Vol. 8,No.2, 217-235.

Al-Hasani, Maulidi. (2016) نظرية المصلحة و دور ها في بناء الأحكام الثرعية. Religia, [S.1.], p. 133-186. April.

Bahsoan, Agil. (2011). Mashlahah Sebagai Maqashid Al Syariah(Tinjauan dalam Perspektif Ekonomi Islam). Universitas Negeri Gorontalo. INOVASI, Volume 8, Nomor 1.

Pahlevi, Farida Sekti. (2016). RevitalisasiPancasilaDalamPenegakanHukum Yang Berkeadilandi Indonesia.Justicia Islamica: Jurnal Kajian Hukum dan Sosial. Vol.13. No.2.

Pardi, I Wayan. (2019). KembaliKepadaUndang-UndangDasar 1945: DiskursusPembukaan UUD 1945 DalamPerspektifSejara.Historia: JurnalPendidikdanPenelitiSejarah, Vol. II, No. 2, 99-101.

Rifandi, Ronal, Rona Rossa, YosiLailaRahmi. KepemimpinandanOptimalisasiPeranAktivisMahasiswa.Matappa: JurnalPengabdianKepadaMasyarakat. Volume 1 Nomor 2.

Zainuddin. (2019). Argumentasi Teori Maslahat Sebagai Ruh Perundang-Undangan. Al Amin:JurnalKajianIlmudanBudaya Islam, Volume 2, No 1.

\section{Buku:}

Herdiawanto, Heri, dkk. (2018). Spritualisme Pancasila. Jakarta: Prenadamedia Group.

LajnahPentashihanMushaf Al-Qur'anBalitbangDiklatKemenag RI. (2019). Al-Qur'an dan Terjemahannya. Jakarta. Kementerian Agama Republik Indonesia.

Mas'udi, Masdar farid. (2013). Syarah UUD 1945 Perspektif Islam. Jakarta: PT. Pustaka Alvabet.

Undang-Undang Dasar Negara Republik Indonesia Tahun 1945. 